\title{
Fecal diversion does not support healing of anus-near pressure ulcers in patients with spinal cord injury-results of a retrospective cohort study
}

\author{
Andreas M. Pussin (iD ${ }^{1}$, Luisa C. Lichtenthäler (D) ${ }^{1}$, Mirko Aach (D) ${ }^{2}$, Thomas A. Schildhauer (D) ${ }^{3}$ and Thorsten Brechmann (D) ${ }^{1 凶}$
}

(c) The Author(s) 2021

STUDY DESIGN: Retrospective cohort study including spinal cord injured patients with anus-near pressure ulcers.

OBJECTIVE: The primary objective was to evaluate the impact of stool diversion via stoma on the decubital wound healing. Secondary objectives included the risk of complications and ulcer recurrence. Associations between the wound healing and potentially interfering parameters were determined.

SETTING: University hospital with a spinal cord injury unit.

METHODS: A total of 463 consecutive patients who presented with a decubitus were retrospectively included. Patients with and without a stoma were compared using descriptive and explorative statistics including multiple regression analysis.

RESULTS: The severity of the pressure ulcers was determined as stage 3 in two-thirds and stage 4 in one-third of all cases. The wound healing lasted longer in the 71 stoma-presenting patients than in the 392 patients with undeviated defecation (77 vs. 59 days, $p=0.02$ ). The age (regression coefficient $b=0.41, p=0.02)$, the ASA classification $(b=16.04, p=0.001)$ and the stage of the ulcers $(b=19.65, p=0.001)$ were associated with prolonged ulcer treatment in the univariate analysis. The multiple regression analysis revealed that the fecal diversion $(b=-18.19, p=0.03)$ and the stage of the ulcers $(b=21.62, p=0.001)$ were the only predictors of delayed wound healing.

CONCLUSION: The presence of a stoma is not related to improved wound healing of ulcers near the anus. On the contrary, stoma patients needed more time until complete wound healing, conceivably related to selection bias. Nonetheless, we currently do not recommend fecal diversion to be the standard concept for decubitus treatment.

Spinal Cord (2022) 60:477-483; https://doi.org/10.1038/s41393-021-00717-2

\section{INTRODUCTION}

Pressure skin ulcers are a common complication and reason for hospitalization in patients with spinal cord injury $(\mathrm{SCl})$ leading to a huge medical, social, and economic burden [1, 2]. The healthcare costs for the treatment of pressure ulcers in $\mathrm{SCl}$ patients are significantly higher than the costs for those without pressure ulcers, partly explained by longer inpatient care [3]. Whereas firstdegree pressure ulcers predominantly in the sacral region dominate within the first 30 days after the initial trauma [4], the risk remains high and varies between 40 and $60 \%$ in the longterm $[5,6]$, covering all different stages of severity; about one-third present with stage 1, about $40 \%$ with stage 2 , and a further $28 \%$ with stage 3 or 4 [5].

Timely care and treatment can reduce the exacerbation of pressure ulcers [7]. The best current preventive approach consists of a risk-adapted lifestyle, including pressure relief, avoidance of promoting risk factors, such as nicotine abuse or alcohol intake, and careful skin monitoring [8]. The concomitant neurogenic bowel dysfunction, fecal incontinence, and defecation difficulties of patients with $\mathrm{SCl}$ are assumed to further aggravate the risk, particularly of sacral ulcerations $[6,9,10]$. Whereas data regarding those with $\mathrm{SCl}$ are missing, fecal incontinence increases the probability of ulcers in the general adult hospitalized population by twenty-two times [11].

Once the ulcer has established, the feces are assumed to deteriorate the healing process [12]. Limited data deriving from a cohort of bedbound patients support better healing and decreased recurrences after colostomy [13]. Therefore, some centers tend to deviate the feces by means of a stoma in order to reduce the risk of contamination. On the other hand, the bowel habit improves over the first six months after injury [14]. Ongoing conservative measures help to control and improve bowel movements [15], whereas the stoma construction cannot completely eliminate secretion and unconscious defecation of residual feces. Additionally, both the surgical procedure and the stoma itself may induce adverse events, such as infections, wound healing disorders, peristomal skin disorders, hernias, or psychological barriers [16]. Up to now, no study has addressed the rationale and risk-to-benefit assessment of this fecal diversion concept in $\mathrm{SCl}$ patients. Hence, as primary objective we aimed to investigate

\footnotetext{
${ }^{1}$ Gastroenterology and Hepatology, Berufsgenossenschaftliche Universitätsklinik Bergmannsheil Bochum gGmbH, Bochum, Germany. ${ }^{2}$ Department of General and Trauma Surgery, Spinal Cord Injury Unit, Berufsgenossenschaftliche Universitätsklinik Bergmannsheil Bochum gGmbH, Bochum, Germany. ${ }^{3}$ Department of General and Trauma Surgery, Berufsgenossenschaftliche Universitätsklinik Bergmannsheil Bochum gGmbH, Bochum, Germany. ${ }^{凶}$ email: thorsten.brechmann@rub.de
}

Received: 9 April 2021 Revised: 19 September 2021 Accepted: 20 September 2021

Published online: 7 October 2021 
the association between the presence of a stoma and the healing process of stage 3 and 4 pressure ulcers in a retrospective cohort study. Secondary objectives were to evaluate the need for revision surgery, the risk of complications, and the duration of intensive care unit stay, and investigated associations between the wound healing and the etiology of the $\mathrm{SCl}$, the localization, the severity, and the age of patients.

\section{PATIENTS AND METHODS \\ Study population and definitions}

We conducted a retrospective cohort study of consecutive $\mathrm{SCl}$ patients who had been hospitalized for surgical pressure ulcer treatment in the $\mathrm{SCl}$ Unit of the University Hospital Bergmannsheil Bochum, Germany, between 2007 and 2017. All adult patients with chronic SCI (for at least 6 months) and a surgical treatment of decubitus stage 3 or 4 according to the National Pressure Ulcer Advisory Panel (NPUAP), European Pressure Ulcer Advisory Panel (EPUAP), and Pan Pacific Pressure Injury Alliance (PPPIA) classification [17] close to the anus were regarded suitable for inclusion.

Regarding patients with multiple treatments, only the first case admitted to our hospital was considered. The severity of the $\mathrm{SCl}$ was classified according to the International Standards for Neurological Classification of Spinal Cord Injury (ISNCSCI) of the American Society of Spinal Cord Injury (ASIA) including the ASIA Impairment Scale (AIS) [18]. Only patients with AIS stage A or B were included.

\section{Clinical data acquisition}

Every case was thoroughly reconstructed based on the electronic data system. Data collection included $\mathrm{SCl}$ characteristics such as etiology, localization, and severity, basic demographic characteristics, stoma characteristics, ulcer characteristics (such as size and stage), and surgical outcome parameters (such as healing time, number of surgical revisions, and complications).

\section{Definition of ulcer characteristics and staging of disability}

The anus-near localization was defined as any ulcer that spread out with at least a substantial surface within the following anatomical structures: The connecting line between both posterior superior iliacal spines formed the cranial margin, the ventrocaudal margin was compartmentalized by the connecting lines between the two ischial tuberosities and the penis root, and the connecting line between the posterior superior iliacal spines and the ischial tuberosities demarcated the lateral margins. The severity level of the ulcers was classified according to the EPUAP, NPUAP, and PPPIA [17]. The healing was evaluated based on the clinical charts; according to standard care patients were discharged with a completely healed ulcer. Therefore, if the detailed description of the achievement of the complete wound healing time was not available, the time of discharge was defined as the endpoint of wound healing. Complications that occurred during ulcer treatment were divided into five severity degrees (Table 1S). A primary colonization was defined by the proof of any microbial species within the pressure ulcer at admission; a subsequent infection with a previously undiagnosed germ was considered as a superinfection. The overall morbidity and periprocedural risk were categorized by the American Society of Anesthesiologists (ASA) score that distinguishes between healthy persons, subjects with mild systemic disease, subjects with severe systemic disease, subjects with severe systemic disease that is a constant threat to life, and moribund persons who are not expected to survive without the operation.

\section{Standard surgical procedure}

Surgical procedures, including the mechanical wound debridement with removal of coatings and necrotic tissue, were realized under general anesthesia. Fascio-cutaneous flaps were typically used to cover tissue defects in areas close to the anus. The fascia was mobilized after skin incision and cutting of the subcutaneous fat by thermocautery. A bridge of skin was kept and the flap was transposed without tension. Redon drains were placed and the flap was fixed in the center with a single button suture. The lateral margins were closed with subcutaneously adapted single button sutures under low tension. Skin sutures were realized by Donati's back-and-forth technique. Finally, a wound dressing and sterile bandage were placed. The therapeutic standard did not change during the observation period; vacuum therapy has never been established as a standard therapy.

\section{Statistics}

Statistical analysis was performed with SPSS Version 26 (IBM, Armonk, USA). Categorial parameters were stated as absolute values and relative frequencies. Median and interquartile range (IQR) were used for the evaluation of metric variables. If necessary, quantitative variables were transferred into numerical categories. Explorative statistics included ANOVA, Fisher's exact test, chi-squared test with Yates correction, twotailed $t$ test, Mann-Whitney $U$ test, and univariate and multivariate regression analysis. In this model, the dummy variables created for the ASA classification led to the exclusion of ASA grade 4 due to a lack of correlation. Results were considered statistically significant with a $p$ value $\leq 0.05$.

\section{Ethical considerations}

The study protocol has been reviewed and approved by the institutional review board of the Ruhr-University Bochum [registry number 18-6351] based on the ethical guidelines of the Declaration of Helsinki and its later revisions. Written, informed consent was obtained from all patients before surgery. Informed consent was neither practicable nor necessary due to its retrospective character.

\section{RESULTS}

\section{Study population}

A total of $463 \mathrm{SCl}$ patients (111 women (24.0\%), median age 53 years (IQR 43-64 years)) of whom 71 patients (15.3\%) carried a stoma were included (Table $2 \mathrm{~S}$ ). The median duration of the $\mathrm{SCl}$ was 222 (76-382) months. Traumatic events were responsible for more than half of the disabilities (60.7\%). Most patients $(n=402$, $86.8 \%)$ presented AIS stage A. There were slight differences between the study groups regarding the etiology and severity of the $\mathrm{SCl}$ with higher grades in the fecal diversion group.

The body mass index was slightly but significantly higher in the stoma presenting patients $\left(26.3(22.1-29.4) \mathrm{kg} / \mathrm{m}^{2}\right.$ vs. 24.2 $\left.(20.5-27.4) \mathrm{kg} / \mathrm{m}^{2}, p=0.04\right)$. The presence of at least one comorbidity differed similarly (95.8 vs. $86.2 \%, p=0.02$ ) (Table 1) with a comparable distribution (Table $3 \mathrm{~S}$ and Fig. 1S). Almost all patients presented as ASA stage 2 (45.8\%) or 3 (52.9\%). The staging differed significantly between the study groups (64.8\% ASA stage 3 in the fecal diversion group vs. $50.8 \%$ ) (Table 1 and Fig. 2S). The medication did not distinguish (Table 4-S). The red blood cell count (Table 5S) was significantly lower among the stoma-treated patients both prior to surgery $(10.9$ vs. $12.1 \mathrm{~g} / \mathrm{dl}, p=0.00005)$ and at discharge (11.2 vs. $12.2 \mathrm{~g} / \mathrm{dl}, p=0.007)$.

\section{Baseline stoma characteristics}

Twenty-six (36.6\%) of the 71 patients with a stoma had been treated with an end colostomy and 17 patients $(23.9 \%)$ with a loop ileostomy. The stoma characteristics for the remaining 28 patients were not documented accurately. There was an average of 40 months (IQR 2.3-156.1) between stoma surgery and admission for ulcer treatment. Eleven of the stoma-treated patients $(25.0 \%)$ had suffered relevant complications during stoma surgery (Table 6-S). The manual evacuation was necessary in 156 patients without a stoma and in only one with a stoma. Sixty-two stoma patients needed neither manual evacuation nor topical or systemic laxatives.

\section{Baseline ulcer characteristics}

The average size of the ulcerations was an estimated 16.0 (8.0$30.0) \mathrm{cm}^{2}$. About 291 of the patients presented a stage 3 and 172 $(37.1 \%)$ a stage 4 decubitus. A total of 246 patients had surgically been pretreated in the same area. At least one pathogen could be detected in 434 patients $(93.7 \%)$ at the start of treatment (Table 7-S). 
Table 1. Basic demographic characteristics.

\begin{tabular}{|c|c|c|c|c|}
\hline & \multirow[b]{2}{*}{$n$} & \multicolumn{3}{|c|}{ Number $(\%)$, Average or Median (IQR) ${ }^{\dagger}$} \\
\hline & & Fecal diversion group & Supported natural defecation group & $p$ value $^{t+}$ \\
\hline Gender [female] & $71 / 392$ & $14(19.9)$ & $97(24.7)$ & 0.36 \\
\hline Body mass index $\left[\mathrm{kg} / \mathrm{m}^{2}\right]$ & $71 / 381$ & $26.3(22.1 ; 29.4)^{*}$ & $24.2(20.5 ; 27.4)$ & 0.04 \\
\hline Duration since SCI [months] & $59 / 346$ & $280(97 ; 406)$ & $219(71.8 ; 380.3)$ & 0.11 \\
\hline Aetiology of $\mathrm{SCl}^{* *}$ & $69 / 362$ & & & - \\
\hline Infection & & $2(2.9)$ & $10(2.8)$ & \\
\hline Neoplasia & & $0(0)$ & $13(3.6)$ & \\
\hline Other & & $31(44.9)$ & $94(26.0)$ & \\
\hline ASIA classification & $68 / 383$ & & & 0.56 \\
\hline Stage A & & $62(91.2)$ & $340(88.8)$ & \\
\hline Stage $\mathrm{E}$ & & $0(0)$ & $0(0)$ & \\
\hline Comorbidities & $71 / 391$ & $68(95.8)^{*}$ & $337(86.2)$ & 0.02 \\
\hline Smoking habit & $60 / 346$ & & & 0.64 \\
\hline Active smoker & & $17(28.3)$ & $88(25.4)$ & \\
\hline Non- smoker & & $43(71.7)$ & $258(74.6)$ & \\
\hline Alcohol consumption & $71 / 392$ & $5(8.5)$ & $25(7.4)$ & 0.76 \\
\hline ASA classification $^{\dagger+* *}$ & $71 / 392$ & & & 0.002 \\
\hline Stage 1 & & $0(0)$ & $0(0)$ & \\
\hline Stage 2 & & $22(31)$ & $190(48.5)$ & 0.004 \\
\hline Stage 3 & & $46(64.8)$ & $199(50.8)$ & 0.03 \\
\hline Adverse event during stoma surgery & 44 & $11(25)$ & $\mathrm{n} / \mathrm{a}$ & - \\
\hline Previously surgical until wound healing & $66 / 379$ & $1(0 ; 2)$ & $1(0 ; 2)$ & 0.31 \\
\hline Previously surgical ulcer procedures & $71 / 392$ & $39(54.9)$ & $207(52.8)$ & 0.74 \\
\hline Severity Ulcer & $71 / 392$ & $71(100)^{*}$ & $392(100)$ & 0.02 \\
\hline Stage 3 & & $36(50.7)$ & $255(65.1)$ & \\
\hline Stage 4 & & $35(49.3)$ & 137 (34.9) & \\
\hline Size Ulcer $\left[\mathrm{cm}^{2}\right]$ & $60 / 329$ & $25(10.5 ; 71.5)^{*}$ & $20(9 ; 35)$ & 0.04 \\
\hline
\end{tabular}

ASA American Society of Anesthesia, ASIA American Spinal Injury Association, $\mathrm{SCl}$ spinal cord injury.

${ }^{+}$as appropriate.

${ }^{+t}$ regardless SCI. Chi2-Test or Mann-Whitney $U$ test, as appropriate.

${ }^{*}$ significant with $p<0.05 .{ }^{* *}$ significant with $p<0.01$.

\section{Outcome of ulcer treatment}

The time to complete wound healing in 445 patients had to be equated with the time of discharge and the healing could not described in 18 patients because they either died in hospital $(n=$ 11) or there was no documentation of the length of the hospital stay $(n=7)$. Prior ulcer treatment did not differ between the two groups. The median duration of ulcer treatment until the wound healed completely amounted to 61 days (IQR 44-89, $n=445$ ) (Table 7S). The stoma group needed an average, though not significantly, of ten days more after the first ulcer perception to surgery than the non-deviating group (70 vs. 60 days, $p=0.64$ ) (Table 2). The length of hospital stay was significantly longer among the stoma-treated patients (78 vs. 59 days, $p=0.003$ ), whereas the need for intensive care treatment was quite similar ( 2.5 days in the stoma group vs. 4.5 days, $p=0.65$ ). Stoma patients needed 77 days (IQR 50-110) to complete wound healing, whereas those without a stoma needed 59 days (IQR 44-86) $(p=0.02)$ (Fig. 1). In a subgroup analysis with a limited number of cases the nature of the stoma did not influence the outcome (Table 3). 
Table 2. Outcome parameters.

\begin{tabular}{|c|c|c|c|c|}
\hline & \multirow[b]{2}{*}{$n$} & \multicolumn{2}{|c|}{ Number $(\%)$ or Median (IQR) ${ }^{\dagger}$} & \multirow[b]{2}{*}{$p$ value ${ }^{t t}$} \\
\hline & & Fecal diversion group & Supported natural defecation group & \\
\hline Admission to surgery time [days] & $39 / 201$ & $70(28 ; 130)$ & $60(27 ; 131)$ & 0.64 \\
\hline Microbial superinfection & $69 / 382$ & $12(17.4)$ & $83(21.7)$ & 0.42 \\
\hline Time to complete wound healing [days] & $66 / 379$ & $77(50 ; 110)^{*}$ & $59(44 ; 86)$ & 0.02 \\
\hline Length of hospital stay [days] & $71 / 390$ & $78(50 ; 118)^{* * *}$ & $59(43 ; 86)$ & 0.003 \\
\hline Adverse events during ulcer treatment & $71 / 392$ & 39 (54.9) & $206(52.6)$ & 0.71 \\
\hline Stage 1 & & $1(2.6)$ & $14(6.8)$ & \\
\hline Stage 2 & & $26(66.7)$ & $150(72.8)$ & \\
\hline Stage 3 & & $3(7.7)$ & $13(6.3)$ & \\
\hline Stage 4 & & $6(15.4)$ & $21(10.2)$ & \\
\hline Clostridioides difficile infection & $71 / 392$ & $2(2.8)$ & $8(2.0)$ & 0.68 \\
\hline Recurrence [within 3 month] & $71 / 392$ & $2(2.8)$ & $11(2.8)$ & 1.00 \\
\hline New ulcer in the same region [within 3 months] & $71 / 392$ & $7(9.9)$ & $23(5.9)$ & 0.21 \\
\hline Recurrence in total & $71 / 392$ & $9(12.7)$ & $34(8.7)$ & 0.40 \\
\hline
\end{tabular}

${ }^{\dagger}$ as appropriate.

${ }^{++}$regardless $\mathrm{SCl}$. Chi ${ }^{2}$-test or Mann-Whitney $U$ test, as appropriate.

* significant with $p<0.05$.

**significant with $p<0.01$

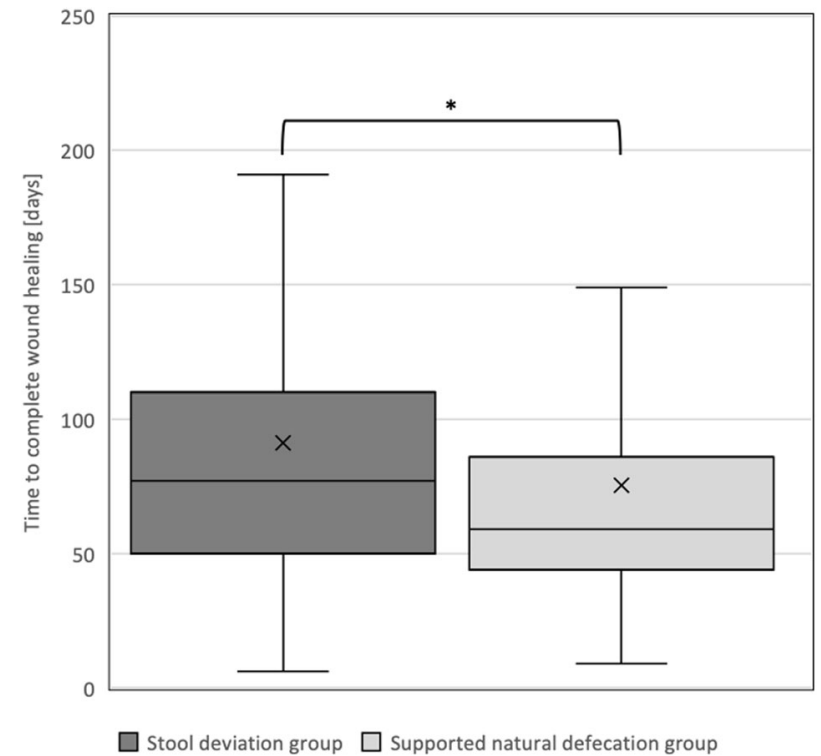

Fig. 1 Duration of complete wound healing. This box plot diagram illustrates that the completion of wound healing lasted significantly longer in patients with fecal diversion than in the natural defecation group ( - median value 77 vs. 59 days [x: arithmetic mean 92 vs. 72 days $] * 0<.05)$. Similarly, the interquartile range varied more widely in the fecal diversion group ([50; 110$]$ vs. [44; 86]).

Ulcer treatment-related complications occurred similarly frequently in both groups. The overall complication rate that included stoma-related adverse events differed tendentially but not significantly (48 complications $(67.6 \%)$ in patients with stoma vs. $221(56.4 \%), p=0.08)$. Thirty-nine subjects $(8.4 \%)$ developed an ulcer recurrence within three months. There were no differences between the two groups $(12.7 \%$ in the stoma group vs. $8.7 \%)$. A total of 95 patients $(20.5 \%)$ developed a superinfection with no differences between the two groups (Table 2).

\section{Ulcer healing influencing factors-time to complete wound healing}

In a linear regression, the age $(p=0.02)$, the ASA classification $(p=0.001)$, and the stage of the ulcers $(p=0.001)$ showed an influence on the time to complete wound healing. The previous stoma treatment $(p=0.03)$ was revealed to be significantly but inversely associated to complete wound healing (Table 4); stoma patients required a longer time to complete wound healing than the supported natural defecation group.

The multiple linear regression model has no autocorrelation (Durbin-Watson statistic 1.725). The $R^{2}$ for the overall model was .141 (adjusted $R^{2}=0.099$ ), indicative of a middle goodness-of-fit, according to Cohen. The stoma and the stage of the ulcers were able to predict hourly wage $(F(8,164)=3.354, p=0.001)$. Therefore, stoma $(p=0.03)$ and the stage of the ulcers $(p=0.001)$ were associated with the wound healing, whereas the ASA classification $(p=0.15)$ and age $(p=0.88)$ lost their significance (Table 4).

\section{DISCUSSION}

This retrospective cohort study aimed to evaluate the concept of fecal diversion to support the wound healing of anus-near pressure ulcers in patients with $\mathrm{SCl}$. Surprisingly, the existence of a stoma was associated with substantially prolonged treatment of the pressure ulcer. The duration until complete wound closure differed remarkably (77 vs. 59 days, respectively). This result contrasts with the findings of a retrospective study on bedridden patients in which the stoma was associated with an accelerated wound healing ( 3 vs. 7 months) and fewer surgical procedures 
Table 3. Subgroup analysis regarding stoma types.

\begin{tabular}{|c|c|c|c|c|}
\hline & \multirow[b]{2}{*}{$n$} & \multicolumn{3}{|c|}{ Number $(\%)$ or Median $\left(\right.$ IQR) ${ }^{\dagger}$} \\
\hline & & End colostomy $n=26$ & Loop ileostomy $n=17$ & $p$ value $^{t+}$ \\
\hline Admission to surgery time [days] & $17 / 7$ & $50(23 ; 90)$ & $90(42 ; 90)$ & 0.52 \\
\hline Primary microbial infection & $26 / 17$ & $26(100)$ & $15(88.2)$ & 0.15 \\
\hline Microbial superinfection & $25 / 17$ & $5(20)$ & $2(11.8)$ & 0.78 \\
\hline Time to complete wound healing [days] & $22 / 17$ & $72.5(50 ; 110)$ & $92(49 ; 179)$ & 0.36 \\
\hline Length of ICU stay [days] & $26 / 17$ & $2(2 ; 13)$ & $4(2 ; 2)$ & 0.52 \\
\hline Adverse events during ulcer treatment & $26 / 17$ & $15(57.7)$ & $8(47.1)$ & 0.71 \\
\hline Adverse events during stoma surgery & $23 / 14$ & $3(13)$ & $4(28.6)$ & 0.39 \\
\hline Adverse events in total & $26 / 17$ & $19(73.1)$ & $11(64.7)$ & 0.81 \\
\hline Clostridioides difficile infection & $26 / 17$ & $1(3.9)$ & $0(0)$ & 1.00 \\
\hline
\end{tabular}

${ }^{+\dagger}$ Easy Fisher Exact Test, $\mathrm{Chi}^{2}$-test with Yates correction or Mann-Whitney $U$ test, as appropriate.

[13]. De la Fuente et al. not only included a much smaller but also a completely different cohort. The $\mathrm{SCl}$ patients in this representative cohort were usually younger, predominantly male, exhibited divergent comorbidities, suffered from immobility but not confinement in bed, loss of sensibility, and defecation problems [19]. Additionally, denervation influences the wound healing negatively $[20,21]$.

The retrospective design bears certain limitations. First of all, the stoma was rarely constructed for the purpose of the current ulcer treatment and contained different types, such as loop ileostomy and end colostomy. The nature of the stoma did not influence the outcome at all in a subgroup analysis with a limited number of cases. Interestingly, the patients with a stoma were more likely to present a stage 4 ulcer, which might reflect slightly divergent patient characteristics and starting conditions. Selfevidently, the stage and size of the pressure ulcer influenced the duration of wound healing. Second, the groups were unequal in size and differed regarding particular basic characteristics. Stoma patients at inclusion presented higher ASA stages (Table 1), reflecting worse clinical performance and slightly more comorbidities. In univariate analysis, both parameters were associated with prolonged ulcer treatment; these associations have already been described by various studies in different contexts both for higher ASA stages [22-24] and comorbidities including anemia $[25,26]$. The stoma patients presented slightly but significantly higher body mass index (BMI) levels ( $26.3 \mathrm{vs.} 24.2 \mathrm{~kg} / \mathrm{m}^{2}$ ); higher BMI levels were related to higher ulcer stages. Although described in previous studies [27], the $\mathrm{BMI}$ in this cohort of $\mathrm{SCl}$ patients was not associated with delayed wound healing. Third, the retrospective design results in a loss of information. The ASA classification, for instance, was only available at the time of inclusion but not of stoma construction. Additionally, the indications for stoma construction remained unclear; it might reasonably be possible that the severity of comorbidities, a lower overall physical performance, or other clinical aspects could have driven the decision in favor of the stoma. Fourth, the cohort has been collected over a whole decade in which the management might have changed slightly, although we did not find any timespecific effects.

The substantial size of the cohort, particularly regarding the rareness of $\mathrm{SCl}$, allowed us to perform a dedicated multiple regression analysis that included all eventually interacting parameters. The calculations revealed that two aspects most of all were reversely associated with the success and duration of the wound healing: The stage of the ulcer $(p=0.001)$ and the presence of a stoma $(p=0.03)$. All other parameters, such as age, clinical performance reflected by the ASA score and ASIA classification, and BMI lost their significance (Table 4). The reason for this remarkable main result that finds support from similar outcomes in patients with an open pelvic fracture [28], remains speculative. Basically, the construction of a stoma is intended to prevent the wound from fecal microbiota, but it is unclear whether the resulting colonization or superinfection plays an important role in the healing process. Additionally, the fecal diversion may alter the colonic microbiota, which sometimes leads to diversion colitis $[29,30]$, and $\mathrm{SCl}$ patients suffer from anorectal alterations such as prolapse and uncontrolled secretion and defecation $[9,10]$, which might allow ongoing contamination and superinfection. Therefore, it seems reasonable to investigate the microbial pattern in the wound before and during treatment in future studies.

The stoma group tended to develop more complications, although not significantly; this observation was triggered exclusively by the adverse events on the occasion of the stoma construction, while complication rates during ulcer treatment did not differ. Regarding the other secondary objectives, such as the need for revision surgery, the duration of intensive care unit stay, the occurrence of sepsis and death, and ulcer relapses, were equally distributed in both groups. Additionally, neither the duration nor the pattern of the $\mathrm{SCl}$ was associated with the outcome of ulcer treatment. Interestingly, we could not even reproduce risk factors that have been associated with deteriorated wound healing, such as smoking [31] and alcohol consumption, in this large $\mathrm{SCl}$ cohort [32].

Although the construction of a stoma showed advantages, such as improved quality of life and social independence, in some studies [33, 34], we cannot recommend this concept as a standard procedure yet. Given the high frequency of anus-near pressure ulcers in $\mathrm{SCl}$ patients $[6,35]$, the potential morbidity of stoma construction $[16,36]$ and the rather prolonged wound healing, the additional stoma constructing surgery should rely on individual decision-making. Additionally, a prospectively designed, controlled study that randomly investigates the influence of a stoma construction, probably standardized as end colostomy, is mandatory in order to evaluate the fecal diverting strategy as a general concept to support wound healing, particularly in $\mathrm{SCl}$ patients. 
A.M. Pussin et al.

Table 4. Ulcer healing influencing factors, simple- and multiple linear regression-Time to complete wound healing [days].

\begin{tabular}{|c|c|c|c|c|}
\hline \multirow[b]{2}{*}{ Parameter } & \multicolumn{2}{|c|}{ Simple linear regression } & \multicolumn{2}{|c|}{ Multiple linear regression ${ }^{A}$} \\
\hline & Regression coefficient & $p$ value $(95 \% \mathrm{CI})$ & Regression coefficient & $p$ value $(95 \% \mathrm{CI})$ \\
\hline ASA classification & 16.04 & $0.001[6.406 ; 25.668]^{* *}$ & 9.28 & $0.15[-3.259 ; 21.818]$ \\
\hline Stoma & -15.79 & $0.03[-30.094 ;-1.481]^{*}$ & -18.19 & $0.03[-34.792 ;-1.594]^{*}$ \\
\hline Smoker & -4.80 & $0.45[-17.255 ; 7.654]$ & 6.03 & $0.40[-8.064 ; 20.114]$ \\
\hline Age [years] & 0.41 & $0.02[0.066 ; 0.749]^{*}$ & 0.04 & $0.88[-0.423 ; 0.494]$ \\
\hline Duration since $\mathrm{SCI}$ [months] & 0.01 & $0.35[-0.016 ; 0.044]$ & -0.001 & $0.97[-0.033 ; 0.032]$ \\
\hline $\begin{array}{l}\text { Time of surgery after the onset of } \\
\text { the ulcer }\end{array}$ & -0.001 & $0.86[-0.015 ; 0.012]$ & 0.03 & $0.07[-0.003 ; 0.057]$ \\
\hline
\end{tabular}

*significant with $p<0.05$.

${ }^{* *}$ significant with $p<0.01$.

\section{CONCLUSION}

To the best of our knowledge, this is the largest study so far and the first study in patients with $\mathrm{SCl}$ that investigates the impact of a stoma in the context of the treatment of anus-near pressure ulcers. The results propose that the presence of a stoma does not support the healing process. Despite all limitations of a retrospective cohort study, the multiple regression analysis indicates that stoma patients need more time until complete wound healing without any other benefits regarding adverse events. Divergent underlying patient characteristics may interfere and play a substantial role. Nevertheless, the data does not support the fecal diversion improving the healing process of anus-near pressure ulcers. Regarding the potential morbidity and psychological restrictions related to the stoma construction, we currently do not recommend it to be the standard strategy and it should rather be based on individual decision-making. A randomized controlled study is mandatory to clarify the impact of the fecal diverting concept in the context of the treatment of anus-near pressure ulcers.

\section{DATA AVAILABILITY}

All data generated or analyzed during this study are included in the submission and appear either in the results or in the supplementary material section. The primary data rests with the corresponding author; all authors have unlimited access. The datasets used and/or analyzed are available from the corresponding author on reasonable request.

\section{REFERENCES}

1. Brem H, Maggi J, Nierman D, Rolnitzky L, Bell D, Rennert R, et al. High cost of stage IV pressure ulcers. Am J Surg. 2009;200:473-7.

2. Filius A, Damen TH, Schuijer-Maaskant KP, Polinder S, Hovius SE, Walbeehm ET. Cost analysis of surgically treated pressure sores stage III and IV. J Plast Reconstr Aesthet Surg. 2013;66:1580-6.

3. Stroupe K, Manheim L, Evans C, Guihan M, Ho C, Li K, et al. Cost of treating pressure ulcers for veterans with spinal cord injury. Spinal Cord Inj Rehabil. 2011;16:62-73.

4. Mawson AR, Biundo JJ Jr, Neville P, Linares HA, Winchester Y, Lopez A. Risk factors for early occurring pressure ulcers following spinal cord injury. Am J Phys Med Rehabil. 1988;67:123-7.

5. Fuhrer MJ, Garber SL, Rintala DH, Clearman R, Hart KA. Pressure ulcers in community-resident persons with spinal cord injury: prevalence and risk factors. Arch Phys Med Rehabil. 1999;74:1172-7.

6. Garber SL, Rintala DH. Pressure ulcers in veterans with spinal cord injury: a retrospective study. J Rehabil Res Dev. 2003;40:433-41.

7. Fatih I, Soysal B, Mert S, Hatice AA, Semra HK. Management and treatment of pressure ulcers: clinical experience. Med Bull Sisli Etfal Hosp. 2019;53:37-41.

8. Gélis A, Dupeyron A, Legros P, Benaïm C, Pelissier J, Fattal C. Pressure ulcer risk factors in persons with spinal cord injury Part 2: the chronic stage. Spinal Cord. 2009;47:651-61.
9. Fajardo NR, Pasiliao R-V, Modeste-Duncan R, Creasey G, Bauman WA, Korsten MA. Decreased colonic motility in persons with chronic spinal cord injury. Am J Gastroenterol. 2003;98:128-34.

10. Preziosi G, Emmanuel A. Neurogenic bowel dysfunction: pathophysiology, clinical manifestations and treatment. Expert Rev Gastroenterol Hepatol. 2009; 3:417-23.

11. Maklebust J, Magnan MA. Risk factors associated with having a pressure ulcer: a secondary data analysis. Adv Wound Care. 1994;7:25, 27-8, 31-47, 25, 27-8, 31-4.

12. Gray M, Giuliano KK. Incontinence-associated dermatitis, characteristics and relationship to pressure injury: a multisite epidemiologic analysis. J Wound Ostomy Cont Nurs. 2018;45:63-67.

13. De la Fuente SG, Levin LS, Reynolds JD, Olivares C, Pappas TN, Ludwig KA, et al. Elective stoma construction improves outcomes in medically intractable pressure ulcers. Dis Colon Rectum. 2003;46:1525-30.

14. Han TR, Kim JH, Kwon BS. Chronic gastrointestinal problems and bowel dysfunction in patients with spinal cord injury. Spinal Cord. 1998;36:485-90.

15. Awad RA. Neurogenic bowel dysfunction in patients with spinal cord injury, myelomeningocele, multiple sclerosis and Parkinson's disease. World J Gastroenterol. 2011;17:5035-5014.

16. Ambe PC, Kurz NR, Nitschke C, Odeh SF, Möslein G, Zirngibl H. Intestinal ostomy: classification, indications, ostomy care and complication management. Dtsch Arztebl Int. 2018;115:182-7.

17. National Pressure Ulcer Advisory Panel. European Pressure Ulcer Advisory Panel and Pan Pacific Pressure Injury Alliance. In Emily Haesler, editor. Prevention and Treatment of Pressure Ulcers: Quick Reference Guide. Osborne Park, Australia: Cambridge Media; 2014.

18. Kirshblum SC, Burns SP, Biering-Sorensen F, Donovan W, Graves DE, Jha A, et al. International standards for neurological classification of spinal cord injury (revised 2011). J Spinal Cord Med. 2011;34:535-46.

19. Qi Z, Middleton JW, Malcolm A. Bowel dysfunction in spinal cord injury. Curr Gastroenterol Rep. 2018;20:47.

20. Barker AR, Rosson GD, Dellon AL. Wound healing in denervated tissue. Ann Plast Surg. 2006;57:339-42.

21. Groah SL, Schladen M, Pineda CG, Hsieh CHJ. Prevention of pressure ulcers among people with spinal cord injury: a systematic review. PM R 2015; 7:613-36.

22. Althumairi AA, Canner JK, Gearhart SL, Safar B, Fang SH, Wick EC, et al. Risk factors for wound complications after abdominoperineal excision: analysis of the ACS NSQIP database. Colorectal Dis. 1026;18:02606.

23. Miller TJ, Jeong HS, Davis K, Matthew A, Lysikowski J, Cho MJ, et al. Evaluation of the American Society of Anesthesiologists Physical Status classification system in risk assessment for plastic and reconstructive surgery patients. Aesthet Surg J. 2014;34:448-56.

24. Wolters $\mathrm{U}$, Wolf $\mathrm{T}$, Stützer $\mathrm{H}$, Schröder T. ASA classification and perioperative variables as predictors of postoperative outcome. Br J Anaesth. 1996;77:217-22.

25. Karahan A, AAbbasoğlu A, Işık SA, Çevik B, Saltan Ç, Elbaş NÖ, et al. Factors affecting wound healing in individuals with pressure ulcers: a retrospective study. Ostomy Wound Manag. 2018;64:32-39.

26. Sanoufa M, Smisson W, Floyd H, Robinson JS. The effect of anaemia on hospital length of stay in lumbar decompression and fusion procedures. J Perioper Pr. 2015;25:267-71.

27. Kayser SA, VanGilder CA, Lachenbruch C. Predictors of superficial and severe hospital-acquired pressure injuries: a cross-sectional study using the International Pressure Ulcer Prevalence survey. Int J Nurs Stud. 2019;89:46-52. 
28. Woods RK, O'Keefe G, Rhee P, Routt ML Jr, Maier RV. Open pelvic fracture and fecal diversion. Arch Surg. 1998;133:281-6.

29. Kleinwort K, Döring P, Hackbarth C, Heidecke CD, Schulze T. Deviation of the fecal stream in colonic bowel segments results in increased numbers of isolated lymphoid follicles in the submucosal compartment in a novel murine model of diversion colitis. Biomed Res Int. 2017;2017:5265969.

30. Tominaga K, Kamimura K, Takahashi K, Yokoyama J, Yamagiwa S, Terai S. Diversion colitis and pouchitis: a mini-review. World J Gastroenterol. 2018;24: 1734-47.

31. Silverstein P. Smoking and wound healing. Am J Med. 1992;93:22S-24S.

32. Radek KA, Matthies AM, Burns AL, Heinrich SA, Kovacs EJ, Dipietro LA. Acute ethanol exposure impairs angiogenesis and the proliferative phase of wound healing. Am J Physiol Heart Circ Physiol. 2005;289:H1084-1090.

33. Branagan G, Tromans A, Finnis D. Effect of stoma formation on bowel care and quality of life in patients with spinal cord injury. Spinal Cord. 2003;41:680-3.

34. Cooper EA, Bonne Lee B, Muhlmann M. Outcomes following stoma formation in patients with spinal cord injury. Colorectal Dis 5 2019;21:1415-20.

35. Garber SL, Rintala DH, Hart KA, Fuhrer MJ. Pressure ulcer risk in spinal cord injury: predictors of ulcer status over 3 years. Arch Phys Med Rehabil. 2000;81:465-71.

36. Krishnamurty DM, Blatnik J, Mutch M. Stoma complications. Clin Colon Rectal Surg. 2017;30:193-200.

\section{ACKNOWLEDGEMENTS}

The authors thank Claudia Dillmann for the support during patient selection. The manuscript has been proofread by a language editing service (Philip Saunders, LL.B., B.Ed., FRSA; Language Support Services; Jablonskistr. 4a; D-10405 Berlin).

\section{AUTHOR CONTRIBUTIONS}

A.M.P.: Conducting the study, acquisition of data, analysis and interpretation, drafting the manuscript; L.C.L.: Conducting the study, acquisition of data, analysis and interpretation, drafting the manuscript; M.A.: Supervision, interpretation of data, revision of the manuscript, support in terms of spinal cord injury; T.A.S.: Supervision, revision of the manuscript, interpretation of data, support in terms of spinal cord injury; T.B.: Idea, conception, and design of the study, data analysis and interpretation, supervision, drafting the manuscript. All authors approved the final manuscript.

\section{FUNDING}

Open Access funding enabled and organized by Projekt DEAL.

\section{COMPETING INTERESTS}

The authors declare no competing interests.

\section{ETHICS APPROVAL}

The study protocol was approved by the institutional review board of the RuhrUniversity Bochum [registry number 18-6351] based on the ethical guidelines of the Declaration of Helsinki and its later revisions.

\section{CONSENT STATEMENT}

Informed consent was obtained from all patients before colonoscopy. Informed consent was neither practicable nor necessary due to its retrospective character.

\section{ADDITIONAL INFORMATION}

Supplementary information The online version contains supplementary material available at https://doi.org/10.1038/s41393-021-00717-2.

Correspondence and requests for materials should be addressed to Thorsten Brechmann.

Reprints and permission information is available at http://www.nature.com/ reprints

Publisher's note Springer Nature remains neutral with regard to jurisdictional claims in published maps and institutional affiliations. cc) (i) Open Access This article is licensed under a Creative Commons Attribution 4.0 International License, which permits use, sharing, adaptation, distribution and reproduction in any medium or format, as long as you give appropriate credit to the original author(s) and the source, provide a link to the Creative Commons license, and indicate if changes were made. The images or other third party material in this article are included in the article's Creative Commons license, unless indicated otherwise in a credit line to the material. If material is not included in the article's Creative Commons license and your intended use is not permitted by statutory regulation or exceeds the permitted use, you will need to obtain permission directly from the copyright holder. To view a copy of this license, visit http://creativecommons. org/licenses/by/4.0/.

(c) The Author(s) 2021 